\title{
Growing pains
}

\section{Protein microarrays are coming of age, and the development of specialized technologies is extending their high-throughput capabilities. Michael Eisenstein reports.}

Like the younger child who has had an older sibling to 'soften up' his or her parents and make life a little easier, protein microarrays have benefited from lessons learned during the noisy adolescence of DNA microarrays. "Intellectually, the assays are identical to DNA microarrays," says microarray pioneer Mark Schena, visiting scholar at TeleChem International in Sunnyvale, California. ${ }^{\text {"T The basic }}$ tenets of miniaturization, automation and parallelism all hold for DNA and protein." Indeed, some tools of the trade, such as array spotters and readers, have needed virtually no changes to make the move to proteins. But the differences are there nonetheless, and the proteinmicroarray field is rapidly developing its own identity, with new challenges that require a diverse set of specialized tools and tricks.

One key distinction emerges early in the analysis process: the selection of array substrate. Unlike oligonudeotides, proteins are broadly heterogeneous in size, shape and chemistry, and the diversity of applications for protein arrays means that users need to shop around for the appropriate substrate. "We usually test about three or four surfaces, and see which one

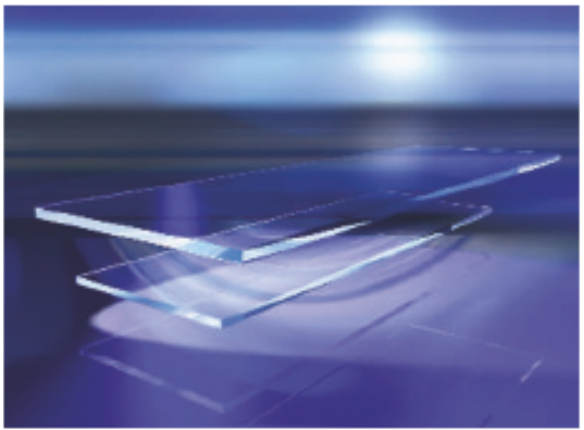

Schott's Slide $\mathrm{H}$ is coated with a hydrogel that is a three-dimensional binding substrate for proteins.

gives us the best signal-to-noise ratio for a given assay," says Michael Snyder of Yale University.

There has been an explosion of options in the market, and several vendors - such as Xenopore of Hawthorne, New Jersey, and Schott of Jena, Germany — specialize almost exclusively in slides and substrates. Functionalized glass surfaces are a strong choice, as they virtually eliminate background fluorescence. According to Schena, TeleChem's SuperEpoxy glass slides are among the company's most popular prod- ucts for protein-array construction. "The key benefit of the epoxide is that it's highly reactive at physiological conditions," he says. "Just depositing proteins on an epoxide-coated surface results in covalent linkage to the glass."

Three-dimensional substrates are also popular. For example, the Nexterion Slide $\mathrm{H}$ from Schott is coated with a covalently linked threedimensional hydrogel with reactive groups that readily bind to proteins or peptides. "Slide $\mathrm{H}$ preserves the three-dimensional structure of proteins, providing a hydrophilic cell-like or cytosol-like environment, thereby maintaining stability and functionality," says Rüdiger Dietrich, Schott's director of research and development and technical support. PamGene of's-Hertogenbosch in the Netherlands also takes advantage of a three-dimensional environment for its flow-through array platform. In its set-up, samples are pumped back and forth through a porous inorganic substrate where capture probes are immobilized.

Nitrocellulose, a timeless classic for protein work, remains among the most popular substrates. "We still don't have a substratum that's better than nitrocellulose for its binding

\section{LOSING THE LABEL}

The appeal of using arrays free from fancy adornments - fluorescent, radioactive or otherwise - is fairly obvious. Such arrays could eliminate extra work and reduce errors in detection and analysis.

Surface plasmonresonance (SPR) is a promising technology for this approach. In SPR the interactants are fixed to a gold-coated substrate, and sample binding is detected as mass concentration-dependent changes in refractive index at that spot, which makes it possible to monitor bind ing in real time. "You canlook at specificity, affinity, kinetics, make concentration measurements, and work in a range of different sample environments," says Gary Franklin, industrial-sector specialistat Biacore.

Recently acquired by GE Healthcare in Little Chalfont, UK, Biacore has pioneered the development of SPRplatforms for a wide variety of proteomics applications. It has two main options for array users. In the Flexchip platform, $\mathbf{4 0 0}$ interactants can be spotted on a slide and then screened againsta singles ample. In contrast, the $\mathrm{A} 100$ is limited to 20 immobilized interactants but, thanks to parallel flow systems, it can perform up to four simultaneous screens with large numbers of samples." The A100 can look at up to 3,800 interactions per day in a variety of different, multiplexed ways," says Franklin.

Lumera of Bothell, Washington, is a relative newcomerto the market. It takes advantage of extremely rapid optical-switching technology, originally developed fortelecommunications, in its Proteomic Processor SPR instrument. Throughput was a key limitation of early SPR array experiments, and Lumera says its switching technology has reduced the problem. "We're basically limited by the size of the slide and

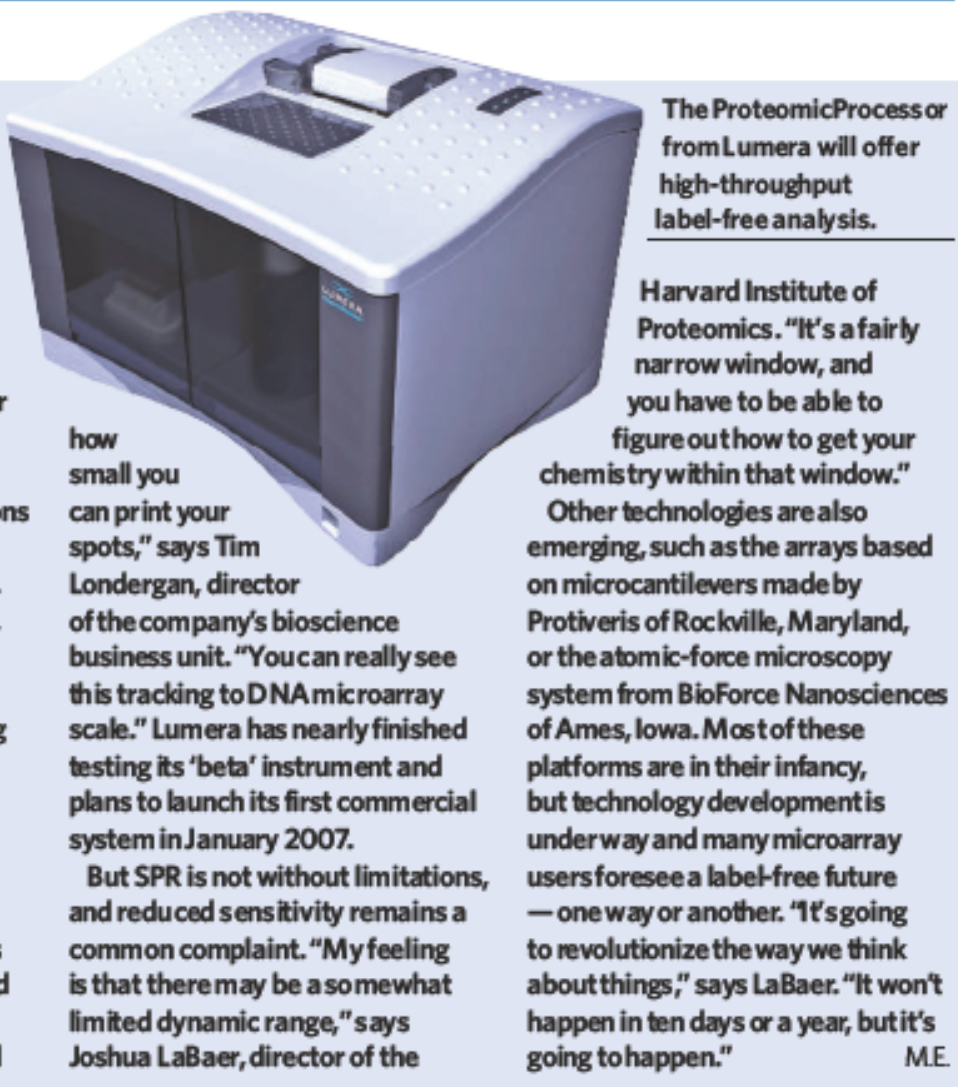

